Камышова Екатерина Викторовна

кандидат социологических наук, доцент, доцент кафедры социальной работь Национального исследовательского Мордовского государственного университета имени Н.П. Огарева

\section{СОЦИАЛЬНАЯ РАБОТА С СЕМЬЯМИ НА РАЗНЫХ СТАДИЯХ РАЗВОДА}

\section{Аннотация:}

В статье раскрывается специфика социальной работы с семьями на разных стадиях развода. В современной России это актуально в связи с высоким уровнем разводимости в стране и одновременно низкой степенью реализации дифференцированного подхода при оказании социальной помощи семьям в предразводной ситуации, в рамках бракоразводной процедуры и в постразводный период. Охарактеризованы особенности социальной проблематики семей на каждой из стадий расторжения брака, определены соответствующие им задачи, направления и технологии социальной работы. Сделан вывод, что учет особенностей жизнедеятельности каждой конкретной семьи при формулировании задач данной деятельности, разработке программ помощи, подборе и использовании технологий, форм и методов поддержки важное условие профилактики и минимизации негативных последствий развода.

Ключевые слова:

развод, стадии развода, предразводная ситуация, бракоразводная процедура, постразводный перuод, семьи при разводе, социальная работа, дифференцированный подход.
Kamyshova Ekaterina Viktorovna

PhD in Social Science,

Associate Professor,

Social Work Department,

National Research Mordovia State University

\section{SOCIAL WORK WITH FAMILIES AT DIFFERENT STAGES OF DIVORCE}

Summary:

The study reveals the specific features of social work with families at different stages of divorce. In modern Russia, this is pivotal due to the high divorce rate and at the same time the low degree of implementation of a differentiated approach when providing social assistance to families in the pre-divorce situation, during the divorce procedures and post-divorce period. The research describes the aspects of the social concerns of families at each stage of divorce as well as defines the corresponding tasks, the scope and technology of social work. The author concludes that it is important to consider the peculiar lifestyle of a family when defining targets in this regard, devising assistance programs, selecting and using technologies, forms and methods of support to minimize the negative consequences of divorce.

Keywords:

divorce, divorce stages, pre-divorce situation, divorce procedure, post-divorce period, families in divorce, social work, differentiated approach.

Социальная работа - один из важнейших социокультурных инструментов помощи семьям при разводе, активно используемый во многих странах мира. К сожалению, в современной России практика применения данного инструмента несовершенна. В числе актуальных проблем слабая реализация в социальной работе с семьями, находящимися на разных стадиях расторжения брака, дифференцированного подхода, который предполагает всесторонний учет особенностей их проблематики при разработке программ помощи, подборе и использовании технологий, форм, методов поддержки. Негативные последствия этой проблемы испытывают на себе тысячи семей, ведь высокий уровень разводимости (процесса расторжения браков в населении или когорте [1]) - одна из основных характеристик социально-демографического развития России и угроза ее национальной безопасности на протяжении уже нескольких десятилетий. С начала 2000-х гг. Россия - лидер по разводимости, и зафиксированный в 2017 г. ее наибольший в мире коэффициент (4,2 развода на 1000 населения) вновь тому подтверждение [2].

Острота и одновременно нерешенность проблемы низкой степени реализации дифференцированного подхода в социальной работе с семьями на разных стадиях расторжения брака неоднократно доказаны результатами прикладных исследований на базе конкретных социальных служб. В частности, об этом свидетельствуют данные проведенного автором статьи в 2017 г. опроса специалистов отделения социальной помощи семье и детям ГБУ РМ «Комплексный центр социального обслуживания по городскому округу Саранск» - базового субъекта социальной работы с семьей в столице Республики Мордовия. Опрошенные специалисты по социальной работе (объем выборки соответствует величине генеральной совокупности - 24 человека) оказались единодушны в том, что практика социальной работы с семьями на разных этапах развода с точки зрения учета особенностей их социальной проблематики несовершенна, следствием чего являются сниженные превентивные и компенсирующие возможности данной деятельности.

Цель статьи - раскрыть специфику социальной работы с семьями на разных стадиях развода. Такой анализ значим как с теоретической, так и с практической точек зрения, поскольку расширяет 
представления о значении и способах оптимизации применения диффреренцированного подхода в социальной работе с семьями, находящимися на разных стадиях бракоразводного процесса.

Развод как способ юридического оформления распада брака на практике - это сложный процесс, состоящий из нескольких стадий, в результате смены которых происходят разрыв брачно-семейных отношений, трансформация социальных статусов, ролей и межличностных связей, а также формирование у членов распавшейся семьи обусловленных этими изменениями особых потребностей во внешней помощи и поддержке. В социологии существуют разные подходы к выделению стадий развода, но чаще всего в работах ученых в качестве основных называются предразводная ситуация, собственно бракоразводная процедура, постразводный период. Обозначив выделенный подход в качестве базового в статье, отметим, что на каждой стадии развода жизнедеятельность семей имеет специфику, следствием которой является формирование у них различных потребностей в помощи.

Профессиональная социальная работа с семьями при разводе представляет собой вид деятельности, нацеленной на профилактику расторжения брака и его негативных последствий, а также решение вызванных им проблем посредством оказания своевременной социально-правовой, социально-психологической, социально-педагогической, медико-социальной, социальнобытовой и иной подобного рода помощи нуждающимся. Между тем на разных стадиях расторжения брака содержательные характеристики социальной работы с семьями имеют отличия.

Основной характеристикой социальной работы с семьями в предразводной ситуации, т. е. при такой степени супружеского конфрликта, которая, с точки зрения мужа и (или) жены, делает неизбежным расторжение брака, является профилактическая направленность. Важно, что в одном случае предразводная ситуация может быть краткосрочной, а в другом (случай «затянувшегося развода») - развивается в несколько отдаленных друг от друга по времени этапов (через принятие супругами или одним из них решения о расторжении брака, прекращение взаимоотношений и установление раздельного проживания, подачу заявления на расторжение брака) и растягивается на годы. Именно поэтому на данной стадии развода первостепенное значение приобретает точная социальная диагностика причин, фракторов, условий возникновения и особенностей протекания конфрликта супругов, который постепенно подводит их к принятию решения о расставании, а также семейных проблем, возникших уже в условиях развития предразводной ситуации. Все это нужно для определения того, действительно ли брак полностью разрушен и лишен смысла для супругов и их детей и какая помощь средствами социальной работы может быть оказана семье.

Если на стадии предразводной ситуации существует хотя бы минимальная возможность сохранения отношений мужчины и женщины в браке, то основная задача социальной работы предотвращение опрометчивого развода. Важно понимать, что решение супругов о разводе может быть принято необдуманно («сгоряча», «назло»), спровоцировано третьими лицами (родственниками, друзьями и др.) или же оформиться под влиянием спорных утверждений («мифов о разводе»), которые выдаются за общеизвестные истины и поддерживают поведение, способствующее разрушению брака (например, «неудачный брак можно исправить только разводом», «мой ребенок справится с родительским разводом, ведь и другие дети с этим справились», «если супруг в новом браке меня полюбит, то он полюбит и моего ребенка» и др.). Развод в таких случаях можно и должно предупреждать, тем более что, по данным социологов, даже через два года о расставании с супругом сожалеют $35 \%$ женщин и 45 \% мужчин; еще свыше 8 \% разведенных женщин и более 9 \% разведенных мужчин не против восстановления разрушенного супружества [3, с. 95]. Поэтому в социальной работе с семьями необходимо отталкиваться от того, что даже полностью сложившаяся, как кажется на первый взгляд, предразводная ситуация не означает абсолютной неизбежности развода [4].

В связи с этим значимы результаты исследований, указывающих на существование причин, по которым россияне готовы сохранить фрактически уже распавшийся брак, в числе которых: общие дети (отмечают 71 \% респондентов), состояние здоровья другого супруга (62), сохраняющиеся чувства к мужу (жене) (62), сложности с разделом жилплощади (43 \%) [5, с. 27].

От специалистов, работающих с семьями, помимо нацеленности на недопущение необдуманного развода, требуется четкое понимание особенностей их жизнедеятельности, таких как, например: явная или неявная ориентация поведения одного или обоих супругов на расторжение брака, возникновение между ними чувства отчужденности и безразличия друг к другу, неравномерное распределение хозяйственно-бытовых ролей и обязанностей по уходу за детьми, различные формы отклоняющегося поведения, большей частью раздельное проведение досуга, отсутствие доверия как между мужем и женой, так и между родителями и детьми и др. Оздоровление ситуации в этих семьях в рамках социальной работы по предупреждению развода требует применения таких технологий, как социальная профилактика, социальное консультирование, социальное посредничество, социальная коррекция, социальная терапия, благодаря которым конфрликтующим супругам, их детям, а также другим вовлеченным в предразводную ситуацию лицам 
оказывается содействие в обучении формам и способам конструктивного разрешения конфликтов, стимулировании развития положительных характеристик взаимодействия, предупреждении возможных последующих отклонений в нем.

В случаях же, если после проведенной социальной диагностики неизбежность развода очевидна и расторжение брака - это хотя и противоречивый, но действительно единственный выход из затянувшегося брачно-семейного кризиса, перед специалистами по социальной работе и привлекаемыми ими к совместной работе представителями других «помогающих» профессий (психологи, педагоги, врачи и т. д.) ставится задача максимально предотвратить негативные последствия уже неизбежной бракоразводной процедуры и постразводного периода для супругов и их детей. Для этого важно настроить разводящихся супругов на конструктивное, как бы странно это ни звучало и трудно ни было, взаимодействие на последующих стадиях развода для сохранения нормальных человеческих отношений и семейных (не супружеских) связей, особенно если в распадающемся браке воспитываются совместные дети.

Отличия социальной работы с семьями, вступившими в стадию собственно бракоразводной процедуры, связаны со сложностями в проведении качественной социальной диагностики переживаемых ими проблем, без которой невозможно точное определение необходимой помощи. Основная причина - краткосрочность бракоразводной процедуры: в органах ЗАГС расторжение брака с последующей выдачей свидетельства производится по истечении месяца со дня подачи соответствующего заявления [6, ст. 22]; если же дело о расторжении брака рассматривается в суде, то суд вправе принять меры к примирению супругов и отложить разбирательство дела, назначив им срок для примирения в пределах трех месяцев [7]. Серьезными факторами, влияющими на содержание и практику социальной работы на этой стадии развода, являются также проявление разводящимися супругами трудно контролируемых негативных чувств и эмоций, отказ многих из них в этой кризисной, стрессовой ситуации идти на контакт со специалистами социальных служб. Несмотря на это, социальная работа на этапе бракоразводной процедуры необходима. Ее объектом являются семьи, в которых супруги приняли твердое решение о разводе. Это семьи, в которых: 1) супруги подали заявление о расторжении брака в орган ЗАГС или суд (в зависимости от отсутствия или наличия совместных несовершеннолетних детей и взаимных обязанностей и претензий друг к другу); 2) бракоразводные дела супругов уже рассматриваются в суде; 3) суд принял меры к примирению супругов и в связи с этим временно отложил разбирательство дела.

Немногочисленные прикладные исследования, посвященные анализу жизнедеятельности выделенных типов семей, подтверждают актуальность для них социально-психологических, социально-педагогических, социально-правовых, материально-бытовых и других проблем и вопросов. При этом наиболее острыми являются вопросы о том, с кем из супругов будут проживать дети, возможно ли общение отдельно проживающего родителя и его родственников с ребенком, как разделить имущество и жилплощадь, будет ли и каким образом осуществляться выплата алиментов и других форм материального содержания родителю, с которым остался ребенок, и др. В этой ситуации значимым становится применение социально-посреднических, социальноконсультационных, социально-терапевтических и социально-адаптационных форм и методов работы, направленных на сдерживание нежелательного эмоционального накала разводящихся супругов, ориентацию их на совместный поиск обоюдно приемлемых решений по вопросам, связанным с разводом. Если суд принял меры по примирению супругов, важно продолжать социально-профрилактическую работу. В случаях же, когда развод действительно неизбежен, необходимо добиться того, чтобы с его неотвратимостью согласились оба супруга, ведь если решение о расторжении брака принято одним из них, второй считает его виновным и, испытывая чувства потери, беспомощности, ярости, часто не желает идти на компромиссы. Альтернативой негативным эмоциям и реакциям супругов могут стать чувство собственной ответственности за происходящее, новые жизненные цели и ценности, сформированные в процессе оказания помощи. Если в семье есть дети, то усилия специалистов по социальной работе должны быть направлены на облегчение их адаптации к меняющимся на этапе бракоразводной процедуры условиям жизни, помощь в сохранении уважения к обоим родителям, постепенное преодоление их растерянности.

Оптимальным результатом социальной работы на стадии бракоразводной процедуры можно считать сфрормированность у желающих расстаться супругов способности и готовности решать спорные моменты на основе сотрудничества. В рамках проводимой с семьей социальной работы также важно найти ответы на вопросы, возможно ли и (если да) каким образом достигнуть положительных изменений в отношениях супругов после окончания бракоразводной процедуры с позиции минимизации ее негативных последствий.

Наконец, основной задачей социальной работы с семьями в постразводный период является помощь как бывшим супругам, так и их детям в социальной адаптации к жизни после развода. Для этого в работе с расставшимися супругами требуются как минимум: социальная коррекция их реакции на общественное мнение и негативные стереотипы в отношении разведенных; социально-адаптационная помощь в осознании нового социального статуса («разведенный») и при- 
нятии себя в нем; социальное консультирование по проблемам достижения независимости от бывшего супруга и бывшей семьи, а также установления самостоятельного (индивидуального для каждого) стиля жизни; социальное посредничество в выстраивании новых отношений с родственниками бывшего супруга, друзьями, коллегами. Если у разведенных супругов есть совместные дети, то с помощью технологий и методов социальной работы важно добиться понимания ими того, что, перестав быть мужем и женой, они остаются родителями. Ребенку важно знать, что, несмотря на развод, у него есть семья, ведь именно «она как социальная общность выступает первичным звеном, фрормирующим связь личности с обществом» [8, с. 38]. Особое значение приобретает вооружение бывших супругов знаниями, навыками и умениями, необходимыми для обеспечения должного участия каждого из них в жизни детей после развода, а также для достижения необходимого уровня взаимодействия в вопросах их материального обеспечения и воспитания.

Особым содержанием наполнена социальная работа с неполными семьями, возникшими вследствие развода. В большинстве своем образующие их одинокий родитель и ребенок (дети) нуждаются в помощи, ориентированной: на преодоление психологической травмы развода; решение финансовых и материальных трудностей, вызванных формированием семейного бюджета преимущественно из доходов только одного родителя; устранение хозяйственно-бытовых сложностей, возникших из-за раздела совместного имущества, переезда и др.; решение медико-социальных проблем, возникших или обострившихся из-за стрессовой ситуации при разводе; взыскание алиментов и т. д. Особое внимание со стороны специалистов по социальной работе должно уделяться «детям развода», чьи проблемы связаны с подорванным доверием к родителям, психологическими расстройствами, асоциальным поведением, нарушениями полоролевой идентифрикации, формированием негативных образцов будущего семейного поведения и т. д.

Таким образом, специфика социально-правовых, социально-бытовых, социально-психологических, социально-педагогических и иных проблем семей на разных стадиях развода предопределяет отношение к ним как к объекту дифференцированной социальной работы. Всесторонний учет особенностей их социальной проблематики при формулировке задач данной деятельности, подготовке программ помощи, подборе и использовании технологий, форм и методов поддержки - важное условие ее эфффективности и результативности. Конечно, возможности специалистов по социальной работе в предупреждении и решении проблем семей на разных стадиях развода нельзя абсолютизировать. Диагностика ими проблем семей, находящихся на разных стадиях развода, возможна лишь частично, ведь те живут своей неповторимой жизнью. Но это не значит, что специалисты по социальной работе не должны изучать эти проблемы и при необходимости поддерживать семьи. При грамотном использовании ресурсов, технологий, форм, методов социальной работы они становятся носителями уникальных возможностей, требуемых для изучения особенностей семей на разных стадиях развода, а также активными субъектами деятельности, направленной на профилактику и нейтрализацию негативных последствий расторжения брака.

\section{Ссылки:}

1. Медков В.М. Демография. 2-е изд. М., 2017. 332 с.

2. Демография: браки и разводы [Электронный ресурс] // Федеральная служба государственной статистики : oфиц. сайт. URL: http://www.gks.ru/wps/wcm/connect/rosstat_main/rosstat/ru/statistics/population/demography/ (дата обращения: 10.07.2018).

3. Хачатрян Л.А. Развод - оборотная сторона брака // Вестник Пермского университета. Серия «Философия. Психология. Социология». 2010. Вып. 1 (1). С. 79-98.

4. См.: Oakland T. Divorced Fathers: Reconstructing a Quality Life. N. Y., 1984. 201 p. ; Price S.J., McKenry P.C. Divorce. Newbury Park, CA, 1988

5. Синельников А.Б., Дорохина О.В. Брак и развод с точки зрения формальных и неформальных социапьных норм // Известия Саратовского университета. Серия «Социология. Политология». 2015. Т. 15, № 3. С. 21-28. https://doi.org/10.18500/1818-9601-2015-15-3-21-28.

6. Семейный кодекс Российской Федерации [Электронный ресурс] : федер. закон от 25 дек. 1995 г. № 223-Ф3 : в ред. от 29 дек. 2017 г. : с изм. от 20 июня 2018 г. Доступ из справ.-правовой системы «КонсультантПлюс».

7. Там же.

8. Исманова Н.А. Успех как фрактор развития человека: роль семьи в успешном развитии ребенка // Общество: социология, психология, педагогика. 2018. № 4. С. 38-40. https://doi.org/10.24158/spp.2018.4.6.

\section{References:}

'Demography: marriages and divorces' 2018, Official website of the Federal State Statistics Service, viewed 10 July 2018, <http://www.gks.ru/wps/wcm/connect/rosstat_main/rosstat/en/statistics/population/demography/>, (in Russian).

Ismanova, NA 2018, 'Success as a factor of human development: the role of the family in the successful development of the child', Obshchestvo: sotsiologiya, psikhologiya, pedagogika, no. 4, pp. 38-40. https://doi.org/10.24158/spp.2018.4.6.

Khachatryan, LA 2010, 'Divorce as a reverse side of marriage', Vestnik Permskogo universiteta. Seriya "Filosofiya. Psikhologiya. Sotsiologiya", iss. 1 (1), pp. 79-98, (in Russian).

Medkov, VM 2017, Demography, 2nd ed., Moscow, 332 p., (in Russian)

Oakland, T 1984, Divorced Fathers: Reconstructing a Quality Life, New York, 201 p.

Price, SJ \& McKenry, PC 1988, Divorce, Newbury Park, CA.

Sinelnikov, AB \& Dorokhina, OV 2015, 'Marriage and Divorce in Russia in the View of Formal and Informal Social Regulations', Izvestiya Saratovskogo universiteta. Seriya "Sotsiologiya. Politologiya", vol. 15, no. 3, pp. 21-28. https://doi.org/10.18500/1818-9601-2015-15-3-21-28. 